\title{
Health-related quality of life in the Brazilian Amazon: a population-based cross-sectional study
}

\author{
Marcus Tolentino Silva ${ }^{1 *}$, Monica Caicedo Roa ${ }^{2}$ and Tais Freire Galvao ${ }^{3}$
}

\begin{abstract}
Background: To analyze perceptions of health-related quality of life and associated factors in populations from the Manaus Metropolitan Region.

Methods: We conducted a population-based cross-sectional study from May to August 2015. Adults aged 18 years and older were selected using probabilistic three-phase cluster sampling and stratified by sex and age, based on official estimates. Quality of life data were collected using the European Quality of Life 5-Dimensions 3-Levels (EQ-5D-3L) along with socioeconomic, demographic, and health perception data. Utility scores were calculated using the Brazilian version of the EQ-5D-3L. Descriptive statistics were derived, and a multivariate Tobit regression model with correction for complex sampling was performed to identify the variables that influence utility levels.

Results: A total of 4001 participants were included. The average utility score was 0.886 (95\% confidence interval [Cl]: 0. $881-0.890)$ with significant differences according to living area (the capital $(0.882 \pm 0.144)$ or inner cities $(0.908 \pm 0.122$; $p<0.001))$. The dimension for which the highest proportion of people reported moderate to severe problems was pain/discomfort (39\%), followed by anxiety/depression (18\%). Men had a higher quality of life than women $(\beta=0.041$, $p<0.001)$. Not working was a factor that increased quality of life compared with being formally employed $(\beta=0.031$, $p=0.037)$. The poorest people had a lower quality of life than the richest people $(\beta=-0.118, p<0.001)$. Better health perceptions increased utility scores $(p<0.001)$, while being separated decreased the scores $(\beta=-0.052, p=0.001)$.
\end{abstract}

Conclusion: Health-related quality of life in the Manaus Metropolitan Region was high, as expected for the general population, and was higher among individuals who lived in the inner cities, men and those in higher social classes. Gender discrepancies and differences in quality of life between the capital and inner cities should be further investigated.

Keywords: Quality of life, Health behavior, Health care surveys, Patient preference, health status, Brazil

\section{Background}

Quality of life is a broad, multidimensional concept that includes a subjective assessment of positive and negative life aspects [1]. It is a popular term that encompasses the physical, mental and social dimensions of well-being. Aspects such as culture, values and spirituality are also essential components of quality of life and contribute to its complexity [2].

Measures of health-related quality of life refer to the perceptions of an individual or group of individuals of

\footnotetext{
* Correspondence: marcusts@gmail.com

${ }^{1}$ Faculty of Medicine, Federal University of Amazonas, Rua Afonso Pena, 1053, Manaus, Amazonas CEP: 69020-160, Brazil

Full list of author information is available at the end of the article
}

their physical and mental health over time [2]. This estimate is widely accepted as a relevant outcome, and it has been applied to assess needs, measure the burden of disease and disability, guide the use of health resources and assess progress toward achieving health goals $[2,3]$.

Monitoring and analyzing health-related quality of life helps to identify population groups with low perceived quality of life and allows these groups to be prioritized when public health policies are implemented to address risk factors. Additionally, this outcome is relevant in clinical and economic studies [3, 4].

Several instruments have been proposed to measure health-related quality of life, including the European Quality of Life (EuroQol) 5-Dimensions (EQ-5D), a generic 
self-report tool developed by the EuroQol group in 1991 to measure preferences [5]. It has been widely applied in population studies in Europe [6, 7], Latin America [8, 9], China [10], Australia [11, 12] and other countries [13-15]. Recently, its utility scores were validated for the Brazilian population [13], but studies on the quality of life of Brazilians are still scarce.

Manaus is the capital of Amazonas, the largest state in Brazil and the municipality with the sixth-highest percentage of gross domestic product in the country [16]. The main causes of morbidity and mortality are violence, mainly deaths by firearms [17], communicable diseases (tuberculosis, leprosy and HIV/AIDS) and vector-borne diseases (malaria and dengue) [18]. In addition, chronic and neoplastic diseases influenced by environmental factors play an important role [19]. Assessments of the quality of life of the people living in this region remain absent so far. Such appraisals would enable the measurement of the population's health status and allow an understanding of the factors that affect this outcome.

The aim of this study was to analyze the health-related quality of life and associated factors in the population of the Manaus Metropolitan Region through the application of EQ-5D in a large representative survey.

\section{Methods}

\section{Study design}

From May to August 2015, we conducted a cross-sectional, population-based study in the Manaus Metropolitan Region, which includes the capital and seven other municipalities of the state of Amazonas: Careiro da Várzea, Iranduba, Itacoatiara, Manacapuru, Novo Airão, Presidente Figueiredo, and Rio Preto da Eva. The study protocol is available for further information.

\section{Setting}

Manaus is the capital of Amazonas. Since the 1960s, it has witnessed intense migratory flows that have led to unplanned urban sprawl.

Over two million inhabitans live in Manaus Metropolitan Region, more than $60 \%$ of the Amazonas state population [31]. Its main economic activities include the household appliances industry, trade and tourism. Access from other Brazilian areas to these cities is precarious and is available only by river or air. In 2010, the human development index of the city of Manaus was 0.737; for the metropolitan region, it was 0.720 [20]. The present analysis is part of a larger study examining the use of health services and inputs in this region.

\section{Sample size}

To calculate the sample size, we considered the official estimates of the population and an estimated health services use of $50 \%$. We considered an $\alpha$ level of 0.05 , power of $20 \%$, and a design effect of 1.5 . A sample size of 3598 people was calculated with a confidence level of $95 \%$. An additional $10 \%$ of participants were included to compensate for potential losses.

\section{Participants}

Adults aged 18 years old and older were eligible for the study. A probabilistic three-phase cluster sample was performed for the 2647 urban sectors of the Manaus Metropolitan Region. We randomly selected 400 primary sectors and 20 replacements (first phase) in each sector. To select households, we applied systematic sampling (second phase). Finally, we randomly selected individuals from the residences according to predefined quotas of sex and age, based on census tracts' official estimates (third phase).

\section{Variables, data collection and measurement}

The primary outcome was the health-related quality of life, as measured with the mean utility score. For simplicity, "utility score" or "score" are used to refer to "mean utility score". When interpreting the results, such scores are referred to simply as "quality of life".

Data collection was conducted through semi-structured standardized interviews by staff who were previously trained in quantitative research. Social, demographic and economic income data were collected. Detailed information can be found in the previously published protocol.

Socioeconomic data were collected according to the five strata (A to $\mathrm{E}$ ) of the Brazilian economic classification criteria, where A signifies wealthier status and E signifies poorer status [21]. This criterion allows an estimation of the household monthly income in Brazilian real (BRL), which was converted to US dollars (USD) based on the currency of the Central Bank of Brazil on July 1, 2015: 1 USD = 3.1185 BRL).

Self-perceptions of health status were measured with the question "In general, what is your health status?" (possible answers: very good, good, fair, bad, very bad).

Perceptions of quality of life were assessed by applying the 3-level version of the EQ-5D (EQ-5D-3L) in its validated Brazilian Portuguese version [22]. The EQ-5D-3L includes five dimensions with questions regarding physical function and disability (mobility, self-care, pain/discomfort), mental function (anxiety/depression) and social activity (usual activities) [3]. Each dimension includes three levels of responses: $1=$ no problems, $2=$ moderate problems and $3=$ severe problems.

The three levels of responses on the EQ-5D-3L are categorized using one number from 1 to 3 that expresses the level selected for each dimension, and these numbers are then combined to create five numbers representing the respondent's state of health. These combinations range from 11111 (no problems in any dimension) to 
33333 (severe problems in all dimensions), allowing the expression of 243 health states [4]. For instance, state 11123 would indicate no problems with mobility, selfcare, and usual activities, moderate problems with pain/ discomfort, and severe problems with anxiety/depression.

Utility scores were obtained from a validation study that included 9148 people in the state of Minas Gerais and the cities of Rio de Janeiro, Porto Alegre, and Recife [23]. To transform the five-digit health status to health utility values, we used the following formula [23]:

Utility score $=0.851+\left(-0.120^{*} \mathrm{M} 2\right)+\left(-0.363^{*} \mathrm{M} 3\right)+$ $\left(-0.112^{*} \mathrm{SC} 2\right)+\left(-0.218^{*} \mathrm{SC} 3\right)+(-0.097 * \mathrm{UA} 2)+\left(-0.184^{*} \mathrm{UA}\right.$ $3)+(-0.064 * \mathrm{PD} 2)+(-0.168$ *PD3 $)+(-0.050 * \mathrm{AD} 2)+$ $\left(-0.095^{*} \mathrm{AD} 3\right)$.

M: mobility; SC: Self-care; UA: Usual activities; PD: Pain and discomfort; AD: Anxiety/depression; 2, moderate problems in the dimension; 3 , severe problems in the dimension.

\section{Statistical analysis}

We used descriptive statistics for the demographic and socioeconomic qualitative variables of the population, with estimates of absolute and relative frequencies. For the utility scores, the mean, standard deviation and 95\% confidence interval $(\mathrm{CI})$ were calculated.

A multivariate Tobit regression model with limits of 0 and 1 was performed to assess the socioeconomic and demographic variables. This model was chosen considering the facts that the utility variable is censored, is not normally distributed and has ceiling effects. A traditional regression model with least squares estimation was not employed since the coefficients of this analysis could be biased by the true population parameters regardless of sample size [24].

Unavailable data were replaced with missing values for the Tobit models, and no imputations were performed. All variables were included in the adjusted model, which was corrected for the complex sampling method. The analysis was stratified by the total sample, the capital of Manaus and the inner cities. A separate model for women who had been pregnant in the last 12 months was conducted to determine the impact of maternity on quality of life. For the data analysis, we used the statistical program Stata 14.2 [25].

\section{Results}

We invited 5410 people, of whom 1409 refused to participate or were found ineligible. A sample size of 4001 participants was included. Of the evaluated sample, $87 \%$ resided in the capital, and the remaining 522 lived in the inner cities: Careiro da Várzea (41), Iranduba (70), Itacoatiara (134), Manacapuru (140), Novo Airão (20), Presidente Figueiredo (57) and Rio Preto da Eva (40).
The general population characteristics are shown in Table 1 . Both sexes were distributed similarly in the sample, with higher scores for men (unadjusted $p<0.001$ ). The main age group represented was from 25 to 34 years old (28.8\%); utility scores were lower in the higher age groups (unadjusted $p \leq 0.004$ ). People who identified their race as brown (mixed-race) were predominant (72.2\%). The $1 \%$ of participants who identified themselves as indigenous reported the lowest utility scores among the ethnic categories; however, the difference was not significant (0.863; unadjusted $p=0.148$ ).

Half of the sample (47.5\%) had completed their education through high school; this group presented the highest utility scores (0.903) among the education attainment strata, and those with incomplete educational levels showed lower levels of quality of life (unadjusted $p=0.004$ ). Eight-four percent belonged to socio-economic classes $\mathrm{C}, \mathrm{D}$ and $\mathrm{E}$. The higher social classes (A and B1, with average monthly household incomes of USD 2788-6500) represented 3.1\% of the population and had a utility score of 0.930 , which differed significantly from the utility scores of the lower economic classes $\mathrm{C} 2$ (0.884) and $\mathrm{D} / \mathrm{E}$ (0.852; unadjusted $p<0.001$ ). Formally employed participants represented $19 \%$ of the sample and had higher scores (0.907) that differed significantly from the scores of those who were retired or informally employed (unadjusted $p<0.001$ ). Most participants $(66.2 \%)$ identified themselves as being in good or very good health with a utility score of 0.920 , which was significantly higher than the percentage that self-identified as having fair, good, or very bad health (unadjusted $p<0.001$ ).

The mean utility score of the study population was 0.886 (95\% CI: $0.881-0.890$ ), range: -0.189 to 1 . Figure 1 shows the left-skewed distribution (skewness $=-1.48$ ). Half of the participants reported a state of 11111 (no problems in any dimension; 52.6\%). It was possible to identify health states with negative values, representing states worse than death. In the study population, five people rated their quality of life negatively, with healthrelated quality of life scores ranging from -0.026 (33322) to -0.889 (33331).

The dimension for which the highest proportion of people reported moderate to severe problems was pain/ discomfort, followed by anxiety/depression (Fig. 2). Moderate problems with pain/discomfort (state 11121) were reported by $20.2 \%$, and severe problems in this dimension (11131) were reported by $2.12 \% ; 4.89 \%$ reported moderate or severe problems in the anxiety/depression dimension, and two people were rated 33333.

One-third of the young adults (18 to 24 years old) reported some problems in the pain/discomfort dimension, and $15.4 \%$ reported problems with anxiety/depression. This proportion increased in each age group, with a higher proportion of moderate and severe problems in each dimension among people aged 60 years and older (Fig. 3). 
Table 1 Demographic characteristics of the participants $(n=4001)$ and mean utility scores

\begin{tabular}{|c|c|c|c|c|}
\hline Variables & $n$ & $\%^{a}$ & Mean utility scores & $p$ value \\
\hline \multicolumn{5}{|l|}{ Sex } \\
\hline Female & 2113 & 52.8 & 0.872 & Ref. $^{d}$ \\
\hline Male & 1888 & 47.2 & 0.901 & $<0.001$ \\
\hline \multicolumn{5}{|l|}{ Age group (years) } \\
\hline $18-24$ & 838 & 20.9 & 0.912 & Ref. \\
\hline $25-34$ & 1152 & 28.8 & 0.904 & 0.174 \\
\hline $35-44$ & 843 & 21.1 & 0.891 & 0.004 \\
\hline $45-59$ & 772 & 19.3 & 0.858 & $<0.001$ \\
\hline$\leq 60$ & 396 & 9.9 & 0.822 & $<0.001$ \\
\hline \multicolumn{5}{|l|}{ Marital status } \\
\hline Single & 2173 & 54.3 & 0.898 & Ref. \\
\hline Separated/divorced & 260 & 6.5 & 0.843 & $<0.001$ \\
\hline Widowed & 159 & 4.0 & 0.825 & $<0.001$ \\
\hline Married & 1409 & 35.2 & 0.881 & $<0.001$ \\
\hline \multicolumn{5}{|l|}{$\begin{array}{l}\text { Pregnancy } \\
\text { (last } 12 \text { months) }\end{array}$} \\
\hline No & 1890 & 89.5 & 0.870 & Ref. \\
\hline Yes & 223 & 10.5 & 0.891 & 0.051 \\
\hline \multicolumn{5}{|l|}{ Ethnicity } \\
\hline White & 636 & 15.9 & 0.897 & Ref. \\
\hline Black & 300 & 7.5 & 0.904 & 0.196 \\
\hline Asian & 138 & 3.5 & 0.881 & 0.265 \\
\hline Brown & 2886 & 72.2 & 0.882 & 0.012 \\
\hline Indigenous & 41 & 1.0 & 0.863 & 0.148 \\
\hline \multicolumn{5}{|l|}{ Educational level } \\
\hline $\begin{array}{l}\text { Higher education } \\
\text { or above }\end{array}$ & 158 & 4.0 & 0.892 & Ref. \\
\hline High school & 1903 & 47.5 & 0.903 & 0.300 \\
\hline Middle school & 649 & 16.2 & 0.899 & 0.543 \\
\hline $\begin{array}{l}\text { Elementary school } \\
\text { or less }\end{array}$ & 1291 & 32.3 & 0.853 & 0.004 \\
\hline \multicolumn{5}{|l|}{ Work status } \\
\hline Formal & 761 & 19.0 & 0.907 & Ref. \\
\hline Informal & 1149 & 28.8 & 0.882 & $<0.001$ \\
\hline Retired & 315 & 7.9 & 0.808 & $<0.001$ \\
\hline Unemployed & 1199 & 29.9 & 0.890 & 0.034 \\
\hline Does not work & 577 & 14.4 & 0.899 & 0.957 \\
\hline \multicolumn{5}{|l|}{ Social class ${ }^{e}$} \\
\hline A/B1 & 124 & 3.1 & 0.930 & Ref. \\
\hline B2 & 505 & 12.6 & 0.921 & 0.456 \\
\hline $\mathrm{C} 1$ & 862 & 21.5 & 0.905 & 0.032 \\
\hline$C 2$ & 1423 & 35.6 & 0.884 & $<0.001$ \\
\hline $\mathrm{D} / \mathrm{E}$ & 1087 & 27.1 & 0.852 & $<0.001$ \\
\hline
\end{tabular}

Health perception
Table 1 Demographic characteristics of the participants ( $n=4001)$ and mean utility scores (Continued)

\begin{tabular}{|c|c|c|c|c|}
\hline Very good & 471 & 11.9 & 0.920 & Ref. \\
\hline Good & 2175 & 54.3 & 0.921 & 0.514 \\
\hline Fair & 1108 & 27.7 & 0.843 & $<0.001$ \\
\hline Bad & 193 & 4.8 & 0.738 & $<0.001$ \\
\hline Very bad & 54 & 1.3 & 0.607 & $<0.001$ \\
\hline \multicolumn{5}{|c|}{$\begin{array}{l}\text { a Frequency adjusted by sample complex design } \\
\text { bHRQoL values were measured by European Quality of Life 5-Dimensions } \\
\text { 3-Levels instrument and transformed as utility values based on values from a } \\
\text { previous study in the Brazilian population [28] } \\
\text { 'Tobit unadjusted regression analysis } \\
\text { dRef., reference } \\
\text { 'Social class according to the Brazilian criteria of economic classification [26] }\end{array}$} \\
\hline
\end{tabular}

The utility scores of individuals from the capital $(0.882 \pm 0.144)$ were lower than those of people from the interior $(0.908 \pm 0.122, p<0.001)$. We identified 90 health states in the population out of the 243 possibilities using the EQ-5D-3L. In Manaus, 87 health states were reported, while in the inner cities, 25 health states were reported.

The adjusted models showed that men had higher utility scores than women $(\beta=0.041, p<0.001)$. This difference was also observed in analyses of the capital $(\beta=0.038$, $p<0.001)$ and the inner cities $(\beta=0.057, p=0.028$; Table 2 ). Separated/divorced people had a lower quality of life than single people $(\beta=-0.052, p<0.001)$; this difference was significant in the capital $(\beta=-0.046, p=0.008)$ but not in other cities in the area.

Not working, a category that included students and housewives, was a factor that increased utility scores compared with the formally employed in the whole sample ( $\beta=0.031, p=0.037)$, while being retired decreased the scores in the Manaus population $(\beta=-0.050, p=0.036)$ and being unemployed had the opposite effect among the population in the inner cities $(\beta=0.076, p=0.041)$.

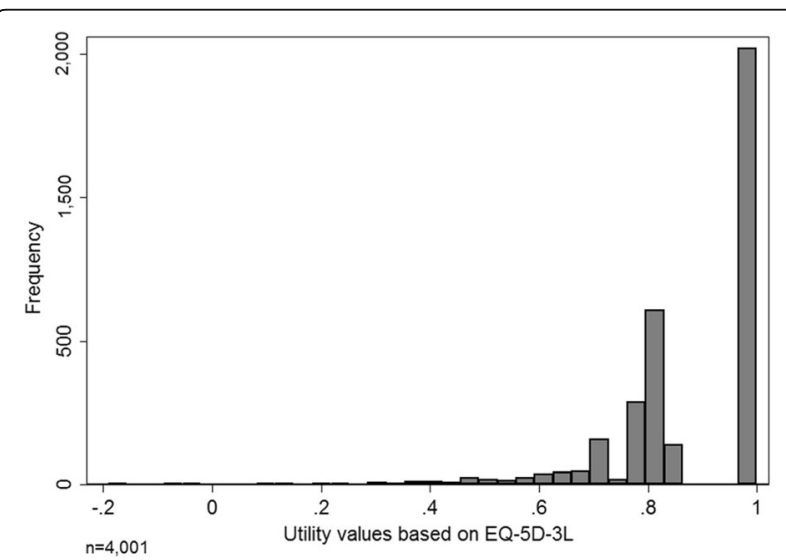

Fig. 1 Distribution of utility scores in the population of Manaus Metropolitan Region, Brazil based on the European Quality of Life 5-Dimensions 3-Levels (EQ-5D-3 L) 


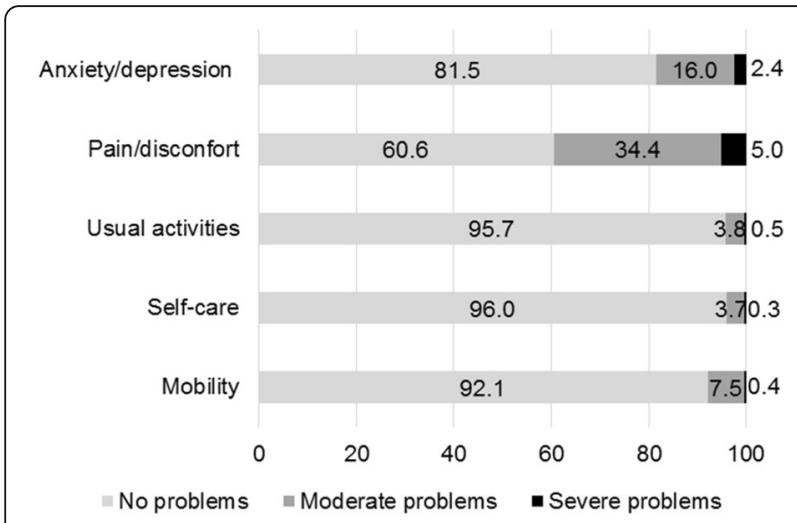

Fig. 2 Self-perceived health of the population of Manaus Metropolitan Region, Brazil according to European Quality of Life 5-Dimensions 3-Levels

Social classes of $\mathrm{C}$ and lower were associated with significantly lower utility scores when compared to the wealthiest class. Belonging to classes D and E represented an adjusted mean reduction of -0.118 in utility scores for the total sample $(p<0.001)$; of -0.103 for the population in Manaus $(p<0.001)$; and of -0.204 for the population in the inner cities $(p=0.041)$.

Those with the poorest self-perceived health had significantly lower utility score in all models. Age, pregnancy, and education did not influence quality of life. With the exception of black people in the inner cities $(\beta=0.148$, $p=0.005)$, race also did not affect the outcome.

\section{Discussion}

Quality of life was higher in the inner cities than in the capital, Manaus. Being male, belonging to higher social classes, reporting better health status and not working increased quality of life. Being separated from a spouse negatively affected the outcome.
We chose the EQ-5D-3L due to its easy and quick application and its broad use in studies worldwide, which allowed for comparisons of populations within and between different countries [9, 26, 27]; however, as a generic instrument, its discriminant ability is lower than that of specific instruments [28, 29]. Another limitation of the present study was the lack of measurements of physical activity, fruit and vegetable consumption, religious beliefs, chronic diseases or leisure time, which are factors that can impact quality of life [30].

A quarter of the invited population refused to participate. Efforts to improve representativeness included the random selection of one subject per household using predefined quotas for sex and age based on the official estimates [31]. Refusal rates in epidemiologic studies are increasing in different contexts due to several factors, including individualism in the society [32].

The mean utility score was 0.886 , representing the expected high quality of life for general population samples, which tend to be elevated [33, 34]. The most affected dimension was pain/discomfort, and the least affected dimensions were self-care and usual activities. These results were consistent with other population-based studies conducted in Brazil in the Federal District [13] and Minas Gerais [35] and in other countries, such as Poland [36], Germany [37], Australia [12] and China [26].

Half of the population mentioned having no problems in any of the dimensions (state 11111), which is expected in a representative sample in which most subjects are healthy. This proportion of healthy subjects was slightly higher than that found in previous studies conducted in Brazil (Minas Gerais, 44.3\%) [35], UK (43\%) [38] and Sweden (46\%) [39]; however, it was lower than the proportion observed in studies conducted in China (87\%) [14], Germany (66\%) [37] and Spain (73\%) [27].

We identified 90 health stages in the population, which was less than in other population-based studies

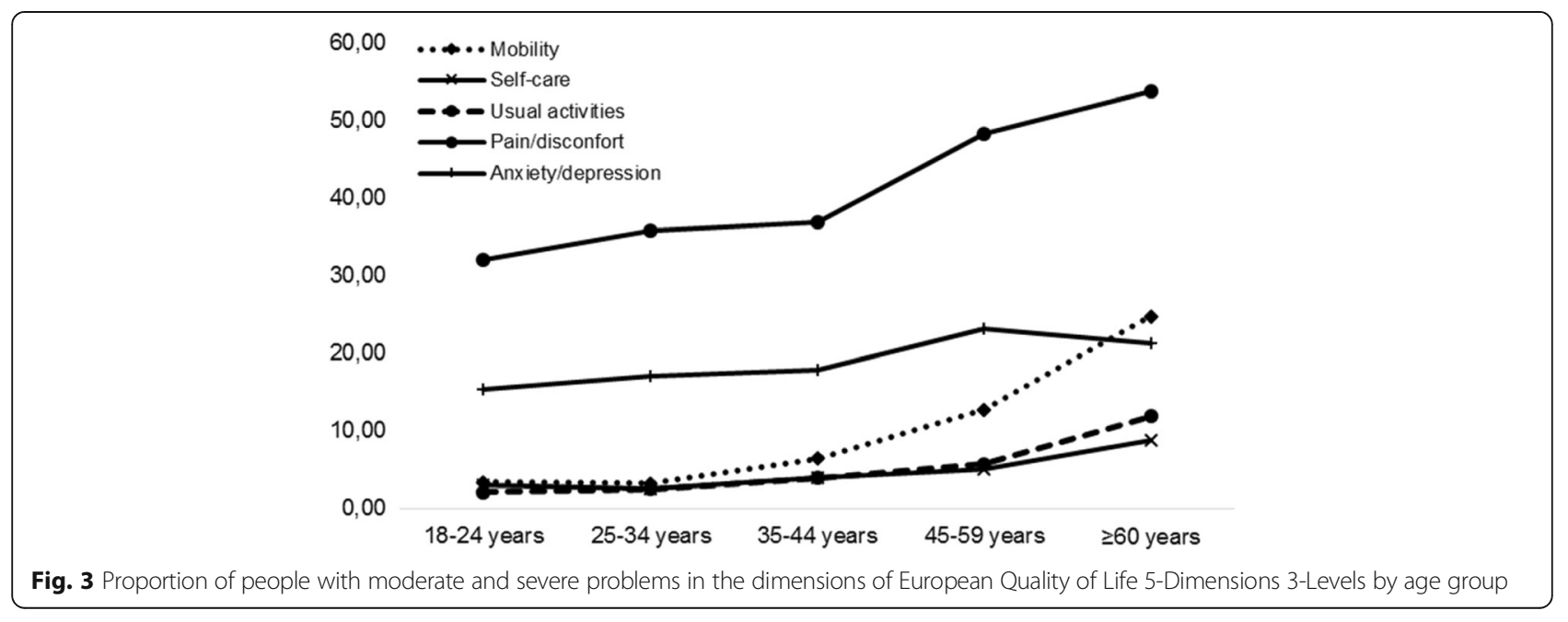


Table 2 Adjusted impact of study variables on utility scores by Tobit regression models of total sample, the capital and and inner cities

\begin{tabular}{|c|c|c|c|c|c|c|}
\hline \multirow[t]{2}{*}{ Variables } & \multicolumn{2}{|l|}{$\begin{array}{l}\text { Total } \\
(n=4001)\end{array}$} & \multicolumn{2}{|l|}{$\begin{array}{l}\text { Manaus } \\
(n=3479)\end{array}$} & \multicolumn{2}{|l|}{$\begin{array}{l}\text { Inner cities } \\
(n=522)\end{array}$} \\
\hline & Coefficient & $p$ value & Coefficient & $p$ value & Coefficient & $p$ value \\
\hline \multicolumn{7}{|l|}{ Sex } \\
\hline Female & Ref. $^{a}$ & & Ref. & & Ref. & \\
\hline Male & 0.041 & $<0.001$ & 0.038 & $<0.001$ & 0.057 & 0.026 \\
\hline \multicolumn{7}{|c|}{ Age group (years) } \\
\hline $18-24$ & Ref. & & Ref. & & Ref. & \\
\hline $25-34$ & -0.002 & 0.849 & -0.005 & 0.692 & 0.006 & 0.858 \\
\hline $35-44$ & -0.004 & 0.787 & 0.001 & 0.972 & -0.028 & 0.461 \\
\hline $45-59$ & -0.028 & 0.053 & -0.026 & 0.089 & -0.054 & 0.164 \\
\hline $60+$ & -0.022 & 0.270 & -0.019 & 0.373 & -0.072 & 0.187 \\
\hline
\end{tabular}

Marital status

Single

Separated/Divorced

Widowed

Married

Pregnancy (last 12 months)

No

Yes

Ethnicity

White

Black

Asian

Brown

Indigenous

Educational level

Higher education or above

High school

Middle school

Elementary school or less

Work status

Formal

Informal

Retired

Unemployed

Does not work

Social class $^{\mathrm{b}}$

$\begin{array}{ll}\text { A/B1 } & \text { Ref. } \\ \text { B2 } & -0.016 \\ \text { C1 } & -0.053 \\ \text { C2 } & -0.081 \\ \text { D/E } & -0.118\end{array}$

Health perception

Very good
Ref.
Ref.

$-0.052$

0.012

$-0.006$

Ref.

$-0.005$

0.789

Ref.

0.036

0.006

$-0.019$

$-0.041$

Ref.

0.029

0.181

0.066

0.79

0.095

0.280

0.042

0.077

0.217

Ref.

$-0.019$

$-0.042$

0.023

0.031

0.114

0.056

0.081

0.037

0.567

0.050

0.002

$<0.001$
Ref.

$-0.046$

0.015

$-0.003$

Ref.

$-0.021$

0.287

0.008

0.578

0.743

Ref.

0.014

0.013

$-0.015$

$-0.057$

Ref.

0.023

0.038

0.017

Ref.

$-0.019$

$-0.050$

0.020

0.029

Ref.

$-0.010$

$-0.043$

$-0.078$

$-0.103$

Ref.

0.589

0.160

0.329

0.497

0.152

0.067

0.005
Ref.

$-0.065$

0.145

0.023

0.748

$-0.008$

0.752

Ref.

0.120

0.065

Ref.

0.148

0.005

$-0.060$

0.431

$-0.029$

0.329

0.011

0.900

Ref.

0.043

0.423

0.052

0.376

0.076

0.173

Ref.

$-0.006$

0.843

0.025

0.672

0.076

0.041

0.069

0.100

Ref.

$-0.053$

0.622

0.732

$-0.108$

0.284

$-0.072$

0.471

$-0.204$

0.041 
Table 2 Adjusted impact of study variables on utility scores by Tobit regression models of total sample, the capital and and inner cities (Continued)

\begin{tabular}{lllllll}
\hline Good & 0.016 & 0.233 & 0.001 & 0.922 & 0.095 & 0.008 \\
Fair & -0.115 & $<0.001$ & -0.133 & $<0.001$ & 0.012 & 0.765 \\
Bad & -0.242 & $<0.001$ & -0.252 & $<0.001$ & -0.169 & 0.005 \\
Very bad & -0.369 & $<0.001$ & -0.379 & $<0.001$ & -0.299 & $<0.001$ \\
\hline
\end{tabular}

${ }^{\mathrm{a}}$ Ref., reference

${ }^{\mathrm{b}} \mathrm{Social}$ class according to the Brazilian criteria of economic classification [23]

$[14,15]$; this result was probably related to sample size. A wider variation of states was observed in the capital than in the inner cities.

The quality of life of women was lower than that of men both in the general model and in the analyses stratified by city. These results were consistent with other studies, in which women reported lower quality of life than men [12, 13, 27, 40]. Factors associated with the lowest health quality in women have been described in terms of access to health services, formal education, physical mobility, sexual restrictions, segregation, less security and informal occupations [41, 42]. These and other factors need to be addressed from the gender perspective to reduce gaps in health equity.

In our population, quality of life decreased nonsignificantly with age. In previous studies, the elderly were the most affected group [12, 26, 30], and age was the most important socio-demographic variable that explained the lowest utility scores [43].

A controversial result found in our study was the higher quality of life of the unemployed in inner cities and of people who did not work for the whole sample. We ran additional analyses separating students from housewives, and the finding of significantly higher quality of life in people who were not working remained $(\beta=0.026, p=0.035)$. Other variables' regression results did not significantly change.

Income positively affected quality of life, while education attainment had no effect on this outcome. Economic resources can affect access to medical care, safer homes and neighborhoods, healthier food, leisure time and physical activity [44]. Higher income is associated to wellbeing and longevity [45]. Conversely, better educated people are more likely to have jobs with healthier working conditions, better health insurance, and higher wages [45].

As expected, higher health perception was associated with higher health-related quality of life. Despite the possible collinearity of independent and dependent variables, self-perception is a personal grade of health, while utility scores from EQ-5D led to a structured reflection of each dimension of the health state. Classic conceptual frameworks consider general health perception and health-related quality of life as distinct but related measures [46].
Quality of life is a measure that is increasingly being introduced as formal evidence to support the decisionmaking process in clinical and public health as well as economic evaluations for the allocation of health resources. Examples of this application are recommendations by the UK National Health Service [47] and New Zealand Pharmaceutical Management Agency [5]. In Brazil, the constitution of the Commission for Incorporating Technology in the Unified Health System is increasingly using cost utility analyses and social preferences to support the decision-making process [48]. In this context, heath-related quality of life studies provides an approximation of health perceptions and supports the development of strategies that positively impact the health of populations and reduce gaps between classes.

This was the first study performed in the Brazilian Amazon to evaluate quality of life in a large sample of the population with good representativeness. The utility scores were based on the Brazilian population [23], providing a more accurate measurement. The regression considered non-normal distributions and expected ceiling effects. The results may be useful for clinical and economic evaluations of health outcomes in Brazil.

\section{Conclusions}

The health-related quality of life of people from Manaus Metropolitan Region is high, as expected for general population. Quality of life was higher among individuals who lived in the inner cities than among those who lived in the capital and was positively influenced by male gender and higher social class. In terms of policy, the present results highlight the need to reduce gender and social inequities in the Manaus Metropolitan Region. Pain and affective domains were the most affected. Gender discrepancies and differences in quality of life between those from the capital and those from inner cities should be further investigated.

\section{Abbreviations}

AD: Anxiety/depression; BRL: Brazilian real; Cl: Confidence interval;

EQ-5D-3L: European quality of Life 5-dimensions 3-levels; HIV/AIDS: Human immunodeficiency virus/Acquired immune deficiency syndrome; PD: Pain and discomfort; SC: Self-care; UA: Usual activities; USD: United States dollars 


\section{Acknowledgements}

Not applicable.

\section{Funding}

This research was funded by National Council for Scientific and Technological Development (Conselho Nacional para o Desenvolvimento Científico e Tecnológico - CNPq), grants 404990/2013-4 and 448093/2014-6.

\section{Availability of data and materials}

The datasets used during the current study are available from the corresponding author upon reasonable request.

\section{Authors' contributions}

MTS and TGF designed the study, analyzed and interpreted the data, and drafted and critically revised the manuscript for important intellectual content. MCR analyzed and interpreted data and drafted the manuscript. All the authors read and approved the final version and agree to be accountable for all aspects of the work by ensuring that questions related to the accuracy or integrity of any part of the work are appropriately investigated and resolved.

\section{Ethics approval and consent to participate}

The ethics committee of the Federal University of Amazonas approved this population-based study with report no. 974,428 on March 3, 2015 (certificate of presentation for ethical appreciation at Brazil Platform [CAAE] 42.203.615.4.0000.5020). The participants provided their consent by signing a document, and confidentiality of their information was guaranteed using cryptography.

\section{Consent for publication}

Not applicable.

\section{Competing interests}

The authors declare that they have no competing interests.

\section{Publisher's Note}

Springer Nature remains neutral with regard to jurisdictional claims in published maps and institutional affiliations.

\section{Author details}

${ }^{1}$ Faculty of Medicine, Federal University of Amazonas, Rua Afonso Pena, 1053, Manaus, Amazonas CEP: 69020-160, Brazil. ²Faculty of Medicine, Clinical Research Institute, National University of Colombia, Calle 30 No. 45-03 Ciudad Universitaria, Bogotá, Colombia. ${ }^{3}$ Faculty of Pharmaceutical Sciences, University of Campinas, Rua Cândido Portinari, 200, Cidade Universitária, Campinas, São Paulo CEP: 13083-871, Brazil.

Received: 27 February 2017 Accepted: 2 August 2017 Published online: 14 August 2017

\section{References}

1. The Whoqol Group. The World Health Organization Quality of Life Assessment (WHOQOL): development and general psychometric properties. Soc Sci Med. 1998;46(12):1569-1585.

2. Carr AJ, Gibson B, Robinson PG. Is quality of life determined by expectations or experience? BMJ: British Medical Journal. 2001;322(7296):1240-1243.

3. Pietersma S, van den Akker-van ME, de Vries M. Generic quality of life utility measures in health-care research: conceptual issues highlighted for the most commonly used utility measures. Int J Wellbeing. 2013;3(2):173-81.

4. EQ-5D-5L User Guide. Basic information on how to use de EQ-5D-3L instrument. Rotterdam: EuroQol Research Foundation; 2015. https:/euroqol.org/wp-content/ uploads/2016/09/EQ-5D-3L_UserGuide_2015.pdf. Accessed 8 Aug 2017.

5. Rabin R, de Charro F. EQ-5D: a measure of health status from the EuroQol Group. Ann Med. 2001;33(5):337-343.

6. Bagust A: Improving valuation sampling of EQ-5D health states. Health Qual Life Outcomes 2013, 11:14.(doi):10.1186/1477-7525-1111-1114.

7. Aygören-Pürsün E, Bygum A, Beusterien K, Hautamaki E, Sisic Z, Boysen HB, Caballero T. Estimation of EuroQol 5-dimensions health status utility values in hereditary angioedema. Patient Preference Adherence. 2016;10:1699-707. doi:10.2147/PPA.S100383

8. Augustovski FA, Irazola VE, Velazquez AP, Gibbons L, Craig BM. Argentine valuation of the EQ-5D health states. Value Health. 2009;12(4):587-96. doi:10. 1111/j.1524-4733.2008.00468.x.
9. Zarate V, Kind P, Chuang LH. Hispanic valuation of the EQ-5D health states: a social value set for Latin Americans. Value Health. 2008;11(7):1170-7. doi: 10.1111/j.1524-4733.2008.00349.x.

10. Cheung PW, Wong CK, Samartzis D, Luk KD, Lam CL, Cheung KM, Cheung JP: Psychometric validation of the EuroQoL 5-Dimension 5-Level (EQ-5D-5L) in Chinese patients with adolescent idiopathic scoliosis. Scoliosis Spinal Disord. 2016;11:19. doi:10.1186/s13013-13016-10083-x. eCollection 12016

11. McCaffrey N, Kaambwa B, Currow DC, Ratcliffe J. Health-related quality of life measured using the EQ-5D-5L: south Australian population norms. Health Qual Life Outcomes. 2016;14(1):133. doi:10.1186/s12955-016-0537-0.

12. Clemens S, Begum N, Harper C, Whitty JA, Scuffham PA. A comparison of EQ-5D-3L population norms in Queensland, Australia, estimated using utility value sets from Australia, the UK and USA. Qual Life Res. 2014;23(8):2375-81. doi:10.1007/s11136-014-0676-x.

13. Zimmermann IR, Silva MT, Galvao TF, Pereira MG. Health-related quality of life and self-reported long-term conditions: a population-based survey. Revista Brasileira de Psiquiatria. 2017;39(1):62-68. doi:10.1590/1516-4446-2015-1853.

14. Sun S, Chen J, Kind P, Xu L, Zhang Y, Burström K. Experience-based VAS values for EQ-5D-3L health states in a national general population health survey in China. Qual Life Res. 2015;24(3):693-703.

15. Burström K, Sun S, Gerdtham UG, Henriksson M, Johannesson M, Levin L, Zethraeus N. Swedish experience-based value sets for EQ-5D health states. Qual Life Res. 2014;23(2):431-42. doi:10.1007/s11136-013-0496-4

16. Instituto Brasileiro de Geografia e Estatistica. Produto Interno Bruto dos Municipios. Rio de Janeiro: IBGE; 2015. http://www.ibge.gov.br/home/estatistica/ economia/pibmunicipios/2010_2013/default.shtm. Accessed 8 Aug 2017.

17. Campos MR, von Doellinger VOR, Mendes LV, Costa MeF, Pimentel TG, Schramm JM: Morbidity and mortality associated with injuries: results of the global burden of disease study in Brazil, 2008. Cad Saude Publica. 2015; 31(1):121-136. doi:10.1590/0102-311X00191113.

18. Magalhães BM, Siqueira AM, Alexandre MA, Souza MS, Gimaque JB, Bastos MS, Figueiredo RM, Melo GC, Lacerda MV, Mourão MP. P. vivax malaria and dengue fever co-infection: a cross-sectional study in the Brazilian Amazon. PLoS Negl Trop Dis. 2014;8(10):e3239. doi:10.1371/journal.pntd.0003239.

19. Medeiros MS, Sacramento DS, Hurtado-Guerrero JC, Ortiz RA, Fenner AL. Cost of illness attributable to environmental factors in the city of Manaus, state of Amazonas, Brazil. Cien Saude Colet. 2014;19(2):599-608. doi:10.1590/ 1413-81232014192.23012012.

20. Atlas do Desenvolvimento Humano nas Regiões Metropolitadas do Brasil. Brasília: PNUD, Ipea, FJP, 2014. http://atlasbrasil.org.br/2013. Accessed 8 Aug 2017.

21. Associação Brasileira de Empresas de Pesquisa. Critério de Classificação Econômica Brasil. 2015. http://www.abep.org/criterio-brasil. Accessed 8 Aug 2017.

22. Rabin R, De Charro F. EQ-5D: a measure of health status from the EuroQol group. Ann Med. 2001;33(5):337-43. doi:10.3109/07853890109002087.

23. Santos M, Cintra MA, Monteiro AL, Santos B, Gusmao-Filho F, Andrade MV Noronha K, Cruz LN, Camey S, Tura B, et al. Brazilian valuation of EQ-5D-3L health states: results from a saturation study. Med Decis Mak. 2016;36(2):253-63.

24. Scott Long J: Limited outcomes: the Tobit model. In: Regression models for Categrical and Limited Dependent Variables. edn. Edited by publications S. California; 1997: 187-216

25. StataCorp. StataCorp. 2015. Stata statistical software: release 14. College Station: StataCorp LP; 2011

26. Zhang Y, Zhou Z, Gao J, Wang D, Zhang Q, Su M, Li D. Health-related quality of life and its influencing factors for patients with hypertension: evidence from the urban and rural areas of Shaanxi Province, China. BMC Health Serv Res. 2016;16:277. doi:10.1186/s12913-016-1536-X.

27. Bernert S, Fernández A, Haro JM, König HH, Alonso J, Vilagut G, SevillaDedieu C, de Graaf R, Matschinger H, Heider D, et al. Comparison of different valuation methods for population health status measured by the EQ-5D in three European countries. Value Health. 2009;12(5):750-8. doi:10. 1111/j.1524-4733.2009.00509.x.

28. Ferreira LN, Ferreira PL, Ribeiro FP, Pereira LN. Comparing the performance of the EQ-5D-3L and the EQ-5D-5L in young Portuguese adults. Health Qual Life Outcomes. 2016;14:89. doi:10.1186/s12955-016-0491-x.

29. Yfantopoulos JN, Chantzaras AE. Validation and comparison of the psychometric properties of the EQ-5D-3L and EQ-5D-5L instruments in Greece. Eur J Health Econ. 2017;18:519-531. doi:10.1007/s10198-016-0807-0.

30. Vankova D, Kerekovska A, Kostadinova T, Todorova L. Researching healthrelated quality of life at a community level: results from a population survey conducted in Burgas, Bulgaria. Health Promot Int. 2016;31(3):534-41. doi:10. 1093/heapro/dav016. 
31. Instituto Brasileiro de Geografia e Estatística. Censo demográfico de 2010. http://www.ibge.gov.br/home/estatistica/populacao/censo2010/default. shtm. Accessed 8 Aug 2017.

32. Galea S, Tracy M. Participation rates in epidemiologic studies. Ann Epidemiol. 2007;17(9):643-53. doi:10.1016/j.annepidem.2007.03.013.

33. Luo N, Johnson JA, Shaw JW, Feeny D, Coons SJ. Self-reported health status of the general adult U.S. population as assessed by the EQ-5D and health utilities index. Med Care. 2005;43(11):1078-86. doi:10.1097/01.mlr. 0000182493.57090.c1.

34. Revicki DA, Kawata AK, Harnam N, Chen W-H, Hays RD, Cella D. Predicting EuroQol (EQ-5D) scores from the patient-reported outcomes measurement information system (PROMIS) global items and domain item banks in a United States sample. Qual Life Res. 2009;18(6):783-91.

35. Menezes RM, Andrade MV, Noronha KV, Kind P. EQ-5D-3L as a health measure of Brazilian adult population. Qual Life Res. 2015;24(11):2761-76. doi:10.1007/s11136-015-0994-7.

36. Golicki D, Niewada M. General population reference values for 3-level EQ-5D (EQ-5D-3L) questionnaire in Poland. Pol Arch Med Wewn. 2015;125(1-2):18-26. doi:10.20452/pamw.2638.

37. Leidl R, Reitmeir P. A value set for the EQ-5D based on experienced health states: development and testing for the German population. PharmacoEconomics. 2011; 29(6):521-34. doi:10.2165/11538380-000000000-00000.

38. Kind P, Dolan P, Gudex C, Williams A. Variations in population health status: results from a United Kingdom national questionnaire survey. BMJ. 1998; 316(7133):736-41.

39. Burström K J Johannesson M, Diderichsen F. Swedish population health-related quality of life results using the EQ-5D. Qual Life Res. 2001;10(7):621-35. doi:10.1023/A:1013171831202.

40. Konig HH, Bernert S, Angermeyer MC. Health status of the German population: results of a representative survey using the EuroQol questionnaire. Gesundheitswesen. 2005;67(3):173-82.

41. WHO Commission on Social Determinants of Health, Sen G, Östlin P: Unequal, Unfair, Ineffective and Inefficient Gender Inequity in Health: Why it exists and how we can change it. In: Women and Gender Equity Knowledge Network. 2007.

42. Instituto de Pesquisa Econômica Aplicada, ONU Mulheres, Secretaria de Políticas para as Mulheres, Secretaria de Políticas de Promoção da Igualdade Racial. Retrato das desigualdades de gênero e raça. 4 ed. Braślia: Ipea; 2011. http://www. seppir.gov.br/central-de-conteudos/publicacoes/pub-pesquisas/retrato-dasdesigualdades-de-genero-e-raca-4a-edicao.pdf/view. Accessed 8 Aug 2017.

43. Szende A, Janssen B, Cabases J: Self-reported population health: an international perspective based on EQ-5D: Springer Netherlands; 2014. doi:10.1007/978-94-007-7596-1.

44. Braveman P, Gottlieb L. The Social Determinants of Health: It's Time to Consider the Causes of the Causes. Public Health Rep. 2014;129(Suppl 2):19-31.

45. Adler NE, Newman K: Socioeconomic disparities in health: pathways and policies. Health Aff (Millwood). 2002;21 (2):60-76.

46. Wilson IB, Cleary PD. Linking clinical variables with health-related quality of life: a conceptual model of patient outcomes. JAMA. 1995;273(1):59-65. doi:10.1001/jama.1995.03520250075037.

47. Devlin NJ, Parkin D, Browne J. Patient-reported outcome measures in the NHS: new methods for analysing and reporting EQ-5D data. Health Econ. 2010;19(8):886-905. doi:10.1002/hec.1608.

48. Pereira VC, Salomon F, Souza A, Santos VC, Petramale C. Health technology assessment tools for technologies incorporation into public health system. Value Health. 2015;18(7):A560. doi:10.1016/j.jval.2015.09.1819.

\section{Submit your next manuscript to BioMed Central and we will help you at every step:}

- We accept pre-submission inquiries

- Our selector tool helps you to find the most relevant journal

- We provide round the clock customer support

- Convenient online submission

- Thorough peer review

- Inclusion in PubMed and all major indexing services

- Maximum visibility for your research

Submit your manuscript at www.biomedcentral.com/submit
Biomed Central 